\title{
3D MODELLING AND DIGITAL ARCHIVING OF CULTURAL HERITAGE: THE EXAMPLE OF ISMOIL SOMONIY TOMB IN UZBEKISTAN
}

\author{
Ali Ulvi ${ }^{17}$ \\ Fatih Varol $^{18}$ \\ Abdurahman Yasin Yiğit ${ }^{19}$
}

\begin{abstract}
The protection of cultural heritage consists of research, examination, diagnosis, conservation and documentation. The most important factor for the success of the study is the accuracy of the identification and documentation study. In recent years, in addition to traditional documentation studies, technological developments have started to be used in the documentation studies of cultural heritage. These studies have shown themselves in the field of photogrammetry. Photogrammetry is a science that helps to create a precise 3D model of the object by making use of at least two pictures taken from different angles of the object. Photogrammetry increases the possibilities for use in cultural heritage studies, research projects and engineering applications that require highly accurate spatial data.In this study, 3D model of Ismoil Somoniy Tomb/Samanid Mausoleum in Bukhara was made in photomodeler software. All architectural details of the tomb were documented with the help of the model. The digital data obtained as a result of the study can be used by all professional disciplines in the studies related to the subject.
\end{abstract}

Key words: Cultural Heritage, 3D Model, Photogrammetry, Close-Range Photogrammetry, Ismoil Somoniy Tomb

\section{INTRODUCTION}

From the past to the present, historical monuments are subject to many natural or unnatural damages. For this reason, the efforts to protect cultural heritage and inform the next generations about history are acceleration and increasing in importance throughout the world. This increasing importance encourages technology to make these studies on cultural heritage easier and more detailed. This also necessitates the development of measurement and certification systems. The greatest heritage that can be left from past to future is cultural heritage. Historical artefacts, which are witnesses of history, are taken under protection by means of documentation on the digital platform. With the method developed in the digital platform, both the original forms

\footnotetext{
${ }^{17}$ Selçuk University, Hadim Vocational School, Hadim, Konya, Turkey (aliulvi@ selcuk.edu.tr)

${ }^{18}$ Selçuk University, Faculty of Tourism, Department of Gastronomy and Culinary Arts, Konya, Turkey (fvarol@ selcuk.edu.tr)

${ }^{19}$ Geomatic Engineer, Antalya, Turkey (abdurahmanyasinyigit@gmail.com)
} 
of historical artefacts are preserved, and a virtual museum is created. Documentation works both as a basis for the reconstruction of the work in case it is damaged, and it allows examining and analysing the changes that occur in the work (Yakar and Mohammed, 2019).

The preparation of historical and cultural monuments and surveys in restoration projects is one of the important process steps. Photogrammetric methods have been used for many years in the preparation of data (survey and three-dimensional model) which will be the basis for the maintenance and repair of historic monuments. With the development of computer and information technology, classical close-range photogrammetry has been given way to digital close-range photogrammetry. With digital photogrammetry method, all orientation and drawing operations can be performed more easily in the computer environment than the classical method. This method offers many possibilities such as automatic orientation and measurement operations, digital three-dimensional vector data, digital orthophoto, digital surface, and terrain models. As the result obtained products are numerical, these products can be used in different application areas such as three-dimensional modelling, visualization, management and presentation of three-dimensional data in addition to documentation and photogrammetric surveying.

\section{IMPORTANCE OF DIGITAL DOCUMENTATION}

Cultural heritage is one of the most important bridges between the past and the future of humanity. It has an important place in human and individual development. Leaving these heritages to pass on the next generation in accordance with their origin is also an important issue for humanity. UNESCO (United Nations Educational, Scientific and Cultural Organization), ICOMOS (International Council for Monuments and Sites), ISPRS (International Society for Photogrammetry \& Remote Sensing), ICOM (International Council for Museums), ICCROM (International Center for the Conservation and Restoration) of Monuments) and UIA (International Union of Architects) have undertaken tasks related to the protection of world cultural heritage (Callegari, 2003).

Metric, written and visual documentation is used as the basic data for the determination of the current status and problems of cultural heritage and all kinds of conservation activities related to the solution of these problems. It is also an important way of communicating cultural heritage to future generations and introducing it to society. Today, different techniques are used in the documentation of Cultural Heritage and this topic is developing rapidly in parallel with technological developments. In addition to producing information on various physical, social, economic, cultural and historical aspects of cultural heritage at various quality and scale, processing and converting large amounts of data produced into usable 
information is an indispensable requirement for protection. To protect the cultural assets that have universal values, which are accepted as the common heritage of all humanity, to introduce them to the world, to create awareness that will protect the cultural heritage in the society and to provide the necessary cooperation for the preservation, documentation and transfer of the destroyed cultural values to the next generations is one of the biggest tasks falling to mankind.

\section{STUDY AREA}

Bukhara province (Uzbek: Buxoroviloyati / Бухоровилояти) is one of the 12 provinces of Uzbekistan. In the middle-south part of the country, there are borders to Turkmenistan and the surface area of Bukhara is $39.400 \mathrm{~km}^{2}$.

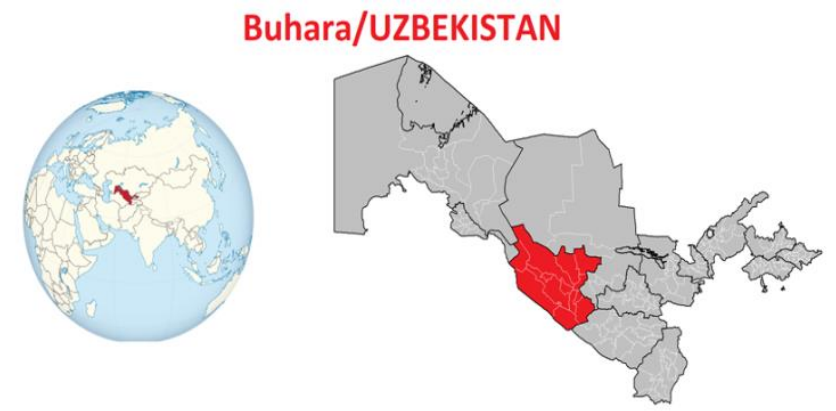

Fig. 1. The Location of Bukhara / Uzbekistan (39 $\left.{ }^{\circ} 46^{\prime} 30^{\prime} \mathrm{N}, 64^{\circ} 26^{\prime} 28^{\prime} \mathrm{E}\right)$ (https://www.wikiwand.com)

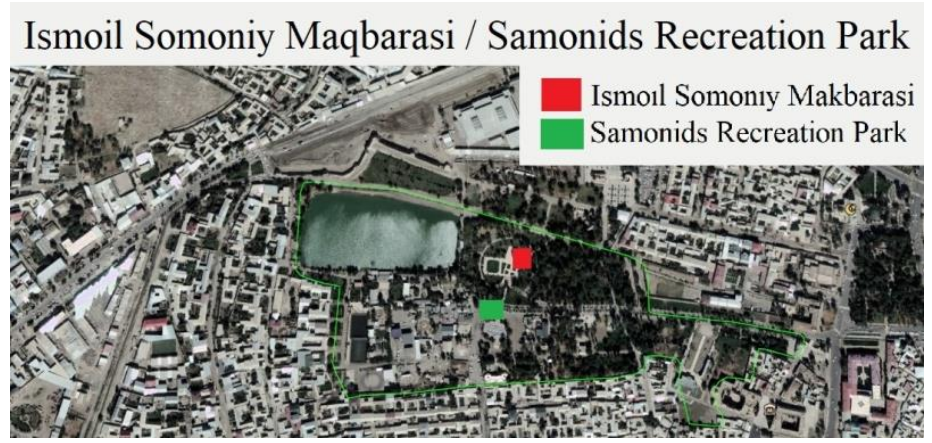

Fig. 2. Ismoil Somoniy Maqbarasi Google Earth location $\left(39^{\circ} 48^{\prime} 36^{\prime} \mathrm{N}, 64^{\circ} 22^{\prime} 2^{\prime} \mathrm{E}\right)$

Located in a park just outside of the touristy area of Bukhara, the Mavzoley Samanidov Mausoleum (also known as the Samanid Mausoleum) provides a bit of solitude from the crowds. It is said to be the tomb of Ismail Samani as well as a few other members of the Samanid dynasty. It was built between 892 and 943. It was rediscovered in 1934 (https://wanderingwheatleys.com).

For many years the lower part of the mausoleum remained under a two-meter high layer of sediment. Now the foundation has been cleared of these obstacles and the mausoleum, fully restored, is open for observation from all sides as was initially 
planned by the builders. The monument marks a new era in the development of Central Asian architecture, which was revived after the Arab conquest of the region.

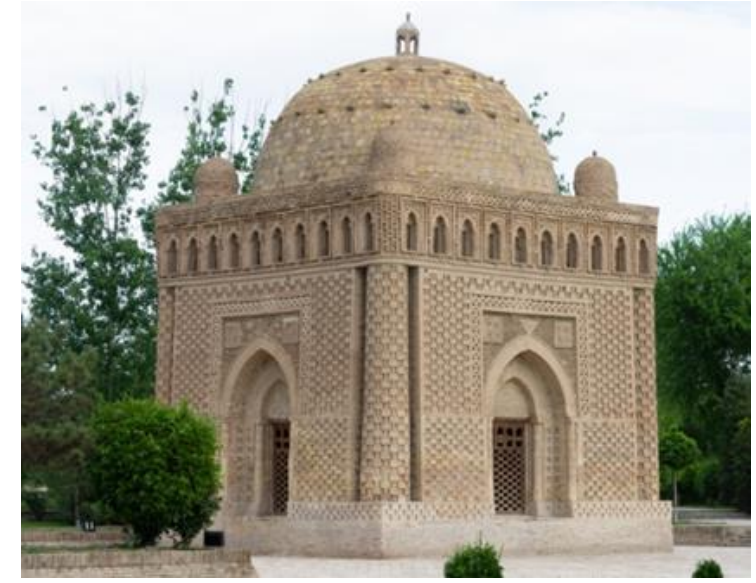

Fig. 3. Ismail Somaniy Maqbarasi/Mavzoley Samanidov Mausoleum (https://www.gpsmycity.com)

The architects continued to use an ancient tradition of baked brick construction, but to a much higher standard than had been seen before.The construction and artistic details of the brickwork are still enormously impressive and display traditional features dating back to the pre-Islamic culture (https://www.gpsmycity.com). Samanid Mausoleum has a square shape, whose side reaches ten meters. It is built from baked bricks. Each of the four sides of the structure is open for inspection. On all peaks are three-quarter columns. There are no decorative supports on them, and there are also no capitals - heads. The filigree arcade, on each side of which there are ten arches, leans onto the columns. The corners of the shelter have small domes. They are slightly shifted to the middle of the axes of the columns. In the center of the roof is the main dome with a small lantern.

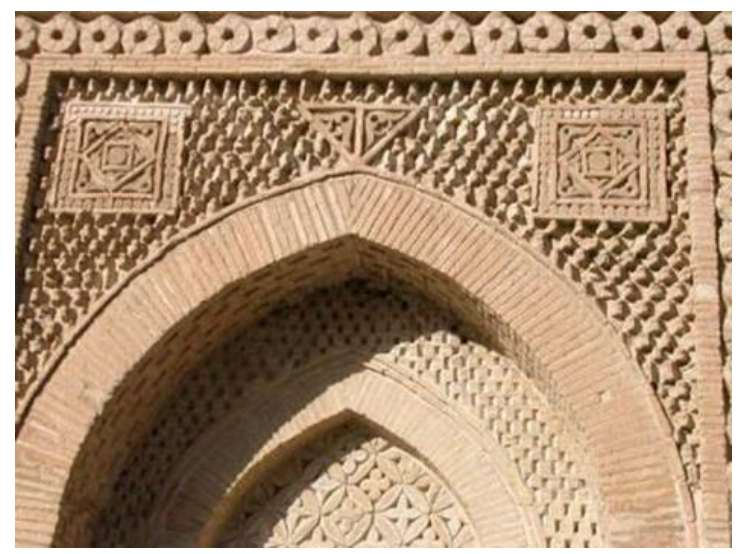

Fig. 4. Ismail Somaniy Maqbarasi Artistic Details 
Samanids Mausoleum (Bukhara) has, as it was already it is said above, four sides, each of which has rectangular doors. They are mounted in a complex frame.The doorway has a decorative outer frame, which first passes into a large, and then into a small keel-shaped arch. The terracotta architectural elements are decorated with the framing of the entrances. Decorative brickwork is the decoration of the rest of the building. Inside the mausoleum has an octagonal shape, which gives it four corner arches (https://vision1cyclings.com).

\section{METHOD AND APPLICATION}

The photogrammetric method is one of the most effective and efficient techniques used in documentation studies. The photogrammetric method is 100-130 times more efficient than conventional methods, 2-5 times more graphically advantageous and 10 times more accurate in terms of accuracy (Sağıroğlu, 2004).

\section{Method}

Close-range photogrammetry is a method for making three-dimensional drawings in close and medium distance areas. Using cameras and special software at different focal lengths, the necessary orientations are made, and three-dimensional models are produced from the photographic surface. With this method, three-dimensional position information of the objects that are created models is obtained (Şanoğlu et al, 2013).

1) Photogrammetry: Photogrammetry word comes from ancient Greek and consists of a combination of the words photos (lights), gramma (line) and metron (measurement) (Marangoz, 2000). According to the definition of ISPRS (International Society for Photogrammetry and Remote Sensing), photogrammetry in its most general sense is "a science that creates and analyses information about the physical object and their environment as a result of recording, measuring and interpretation of photographic images and electromagnetic energy" (Yast1kl1, 2009). The aim of photogrammetry is to obtain the geometric properties of objects or topography with the help of photographs. Photogrammetry is therefore defined as the technique of acquiring information about objects without direct contact with them (Yast1kl1, 2010).

From the photographs taken by photogrammetry method, special equipment and software can be used to produce maps, digital elevation or digital surface models and orthophoto. Digital Elevation Model (DEM) is a numerical representation of the altitude information of the terrain at regular intervals in the $\mathrm{X}$ and $\mathrm{Y}$ direction in a common vertical datum used. Digital Elevation Model generally refers to height information about the bare earth without vegetation and man-made objects. The Digital Surface Model is that the different height information is related to the ground surface of buildings, trees, towers, and other objects. Orthophoto can be defined as a 
re-sampled photograph or image with the geometric characteristics of a map, scaled, skewed, curved and elevated curves in differential areas (Yastıkl, 2009). Photogrammetry technique is frequently preferred in different disciplines. Photogrammetry can be classified according to object size, location of the photographic point and evaluation methods (Atkinson, 1996). In this study, the method of close-range photogrammetry which is based on the location of the photographic point was preferred.

2) Close-range Photogrammetry: Close-range photogrammetry is a method for making three-dimensional drawings in close and medium distance areas. Using cameras and special software at different focal lengths, the necessary orientations are made, and three-dimensional models are produced from the photographic surface. With this method, three-dimensional position information of the objects that are created models is obtained (Şanoğlu et al, 2013).

Terrestrial photogrammetry technique is a method which was used for archaeological measurements and Documentation of historical artefacts for ages. Photogrammetry, along with the development of digital Techniques, became more efficient and economical method documentation and protection of architectural works. Recently, as a result of improvements on "The Investigation of Useability of Non-Metric Digital Cameras Mounted on the Kites Platforms at the Archaeological Documentation Work 229" digital photogrammetry and computer technology, reconstruct-Tuition of buildings as three-dimensional took part amongst Current research topics. Day by day modelling a building as three-dimensional has almost become obligatory for tourism and urban planning (Suveg and Vosselman, 2000).

The most important feature of terrestrial photogrammetry is that data collection and measurement operations are performed in a short time. With the archiving of the data obtained because of photogrammetric measurements, the necessity of making measurements at any time is eliminated. The necessary information is accessed from the archived data. Close-range photogrammetry is therefore often a preferred method (Şanoğlu et al, 2013). One of the most important advantages of close-range photogrammetry is that it allows measurement of inaccessible or dangerous buildings, very high or very low buildings. It is a great convenience to measure the desired parts of the object from photographs (Yakar and Yilmaz, 2008).

\section{Application}

The application part starts with the taking of photographs belonging to the historical work, continues with the 3D model after being processed by means of photogrammetric software and ends with the documenting of the historical artefacts. 
1) Taking photos: In close-range photogrammetry, photo acquisition is performed in three ways according to the condition of the acquisition axes and the basis of shooting. These are normal picture taking, directed picture taking, and convergent picture taking. Of these methods, the most commonly applied is normal intake (Marangoz, 2000). The photographing of the historical structure was performed with the PENTAX Optio RZ18.

Tab. 1. Pentax Optio Rz18 Camera And Specifications

\begin{tabular}{|c|c|}
\hline$(((\mathrm{O}))(16.6$ \\
\hline Total megapixels & PENTAX Optio RZ18 \\
\hline Max. Image resolution & $4608 \times 3456$ \\
\hline Sensor size & $1 / 2.33^{\prime \prime}(\sim 6.08 \times 4.56 \mathrm{~mm})$ \\
\hline Weight & $190 \mathrm{~g}$ \\
\hline Dimensions & $109 \times 61 \times 36 \mathrm{~mm}^{\prime}$ \\
\hline Pixel area & $1.74 \mu \mathrm{m}^{2}$ \\
\hline Pixel density & $57.54{\mathrm{MP} / \mathrm{cm}^{2}}^{2}$ \\
\hline
\end{tabular}

(https://www.digicamdb.com) 


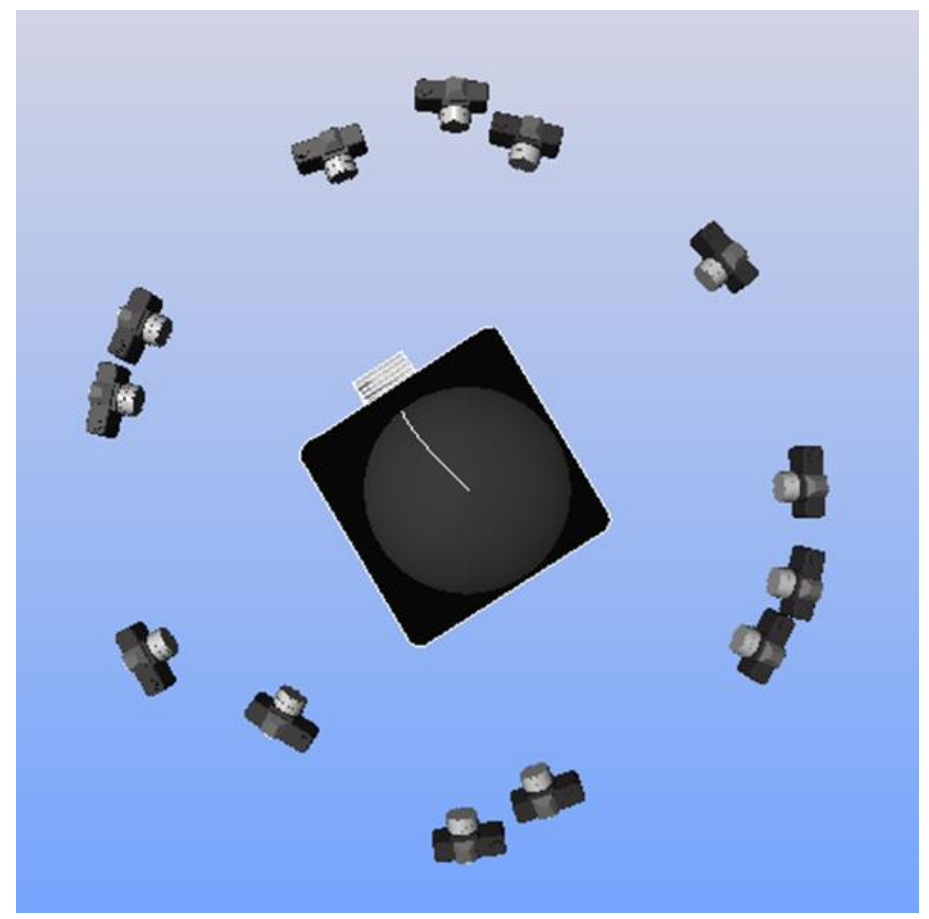

Fig. 5. Photo Shooting Locations

Considerations During Photo Shooting:

- It is necessary to change the shooting position in each photo, as pictures taken only by changing the camera orientation will cause difficulties in stabilizing.

- Photographs should be taken to overlay the whole object and to be superimposed.

- The angle between the two photographs should be a minimum of $30^{\circ}$.

- It must be played back with the camera's zoom setting. It is necessary to take photos at the calibration set.

- Images related to the same surface should be taken with each other at approximately 60 and 70 percent overlap ratio.

2) Processing of Photographs on Digital Platform and Documentation of Historical Artefacts: After the photographing process of the work to be documented is finished, these photographs are transferred to the computer. The photographs are introduced to the photogrammetric evaluation software. A 3D model is created by means of photogrammetric software on 2D images. 


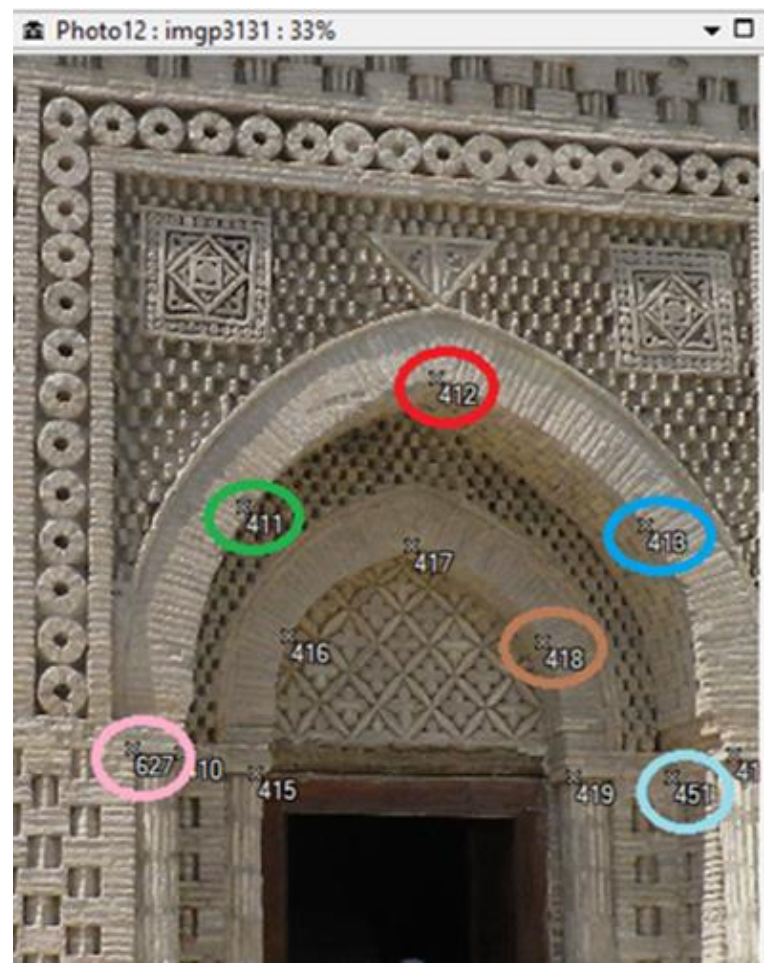

Fig. 6. Point Marking

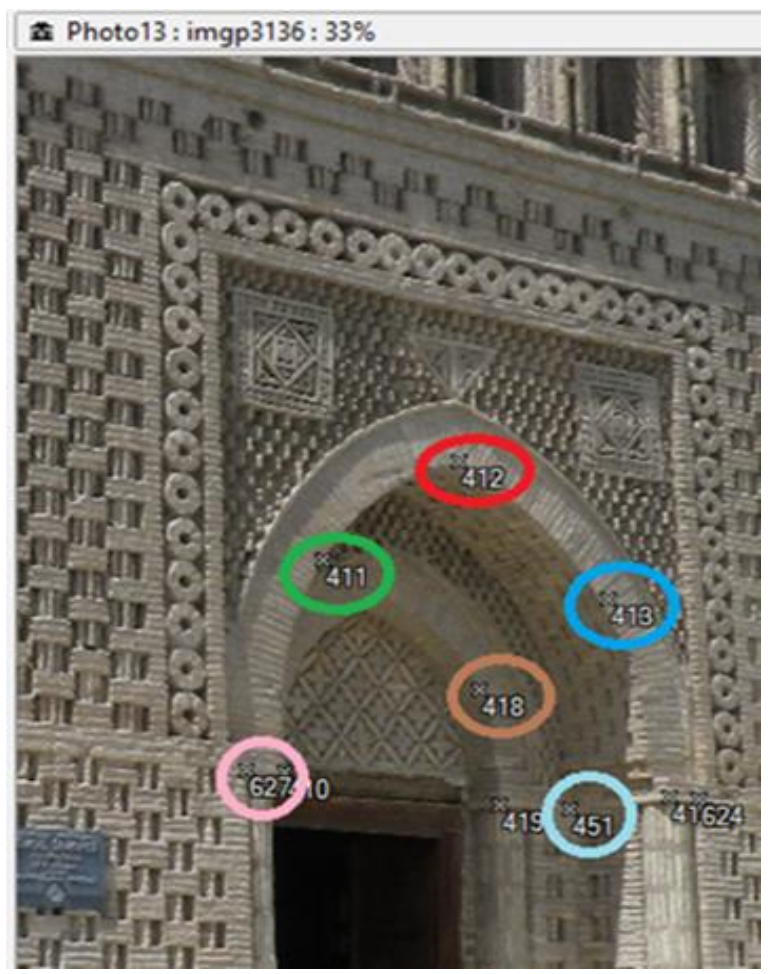

Fig. 7. Point Marking 
As the first step for this process, digital image matching is performed from the pictures taken with overlapping. With digital image matching, conjugate points in two or more images are detected to reveal the surface model of the object (Nurminen, 2013). As shown in figure 6 and figure 7, the conjugate points are marked with precision. When marking the points, attention is paid that the marked point can be selected in each photo. Then, the paired photos are subjected to orientation. After the orientation process is completed, details are drawn, and the surface coating is performed. To do this, two photos will be opened coating the same area. Drawing is made on the reference photo; this drawing is copied, and its location is shown on the other photo and a 3D drawing of the artefact is obtained in figure 8 .

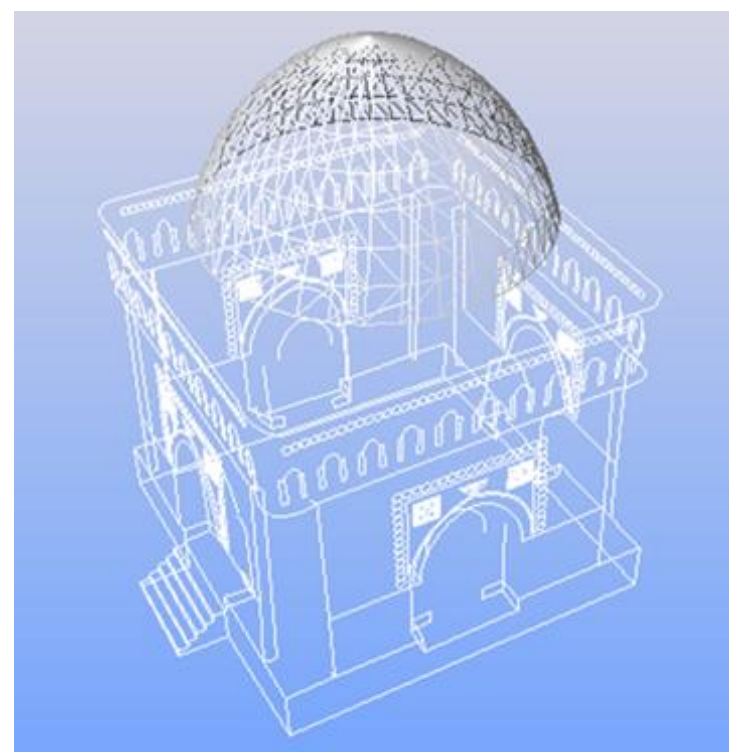

Fig. 8. Drawing Process

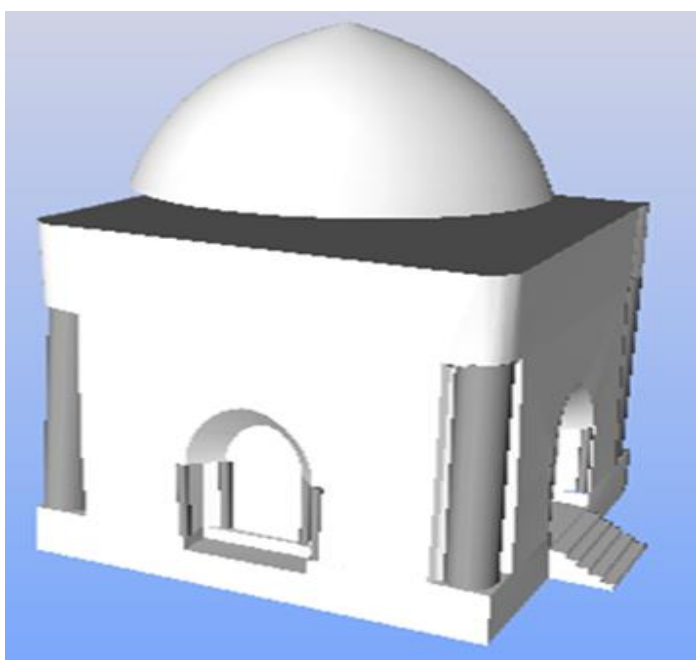

Fig. 9. Surface Coating 
After the drawing process is completed, the surface coating of the model is made over the photographs and the model becomes final and we give our 3D model a highquality image. The surface-coated version of the model is shown in figure 9. All details of the artefact are drawn in figure 10.

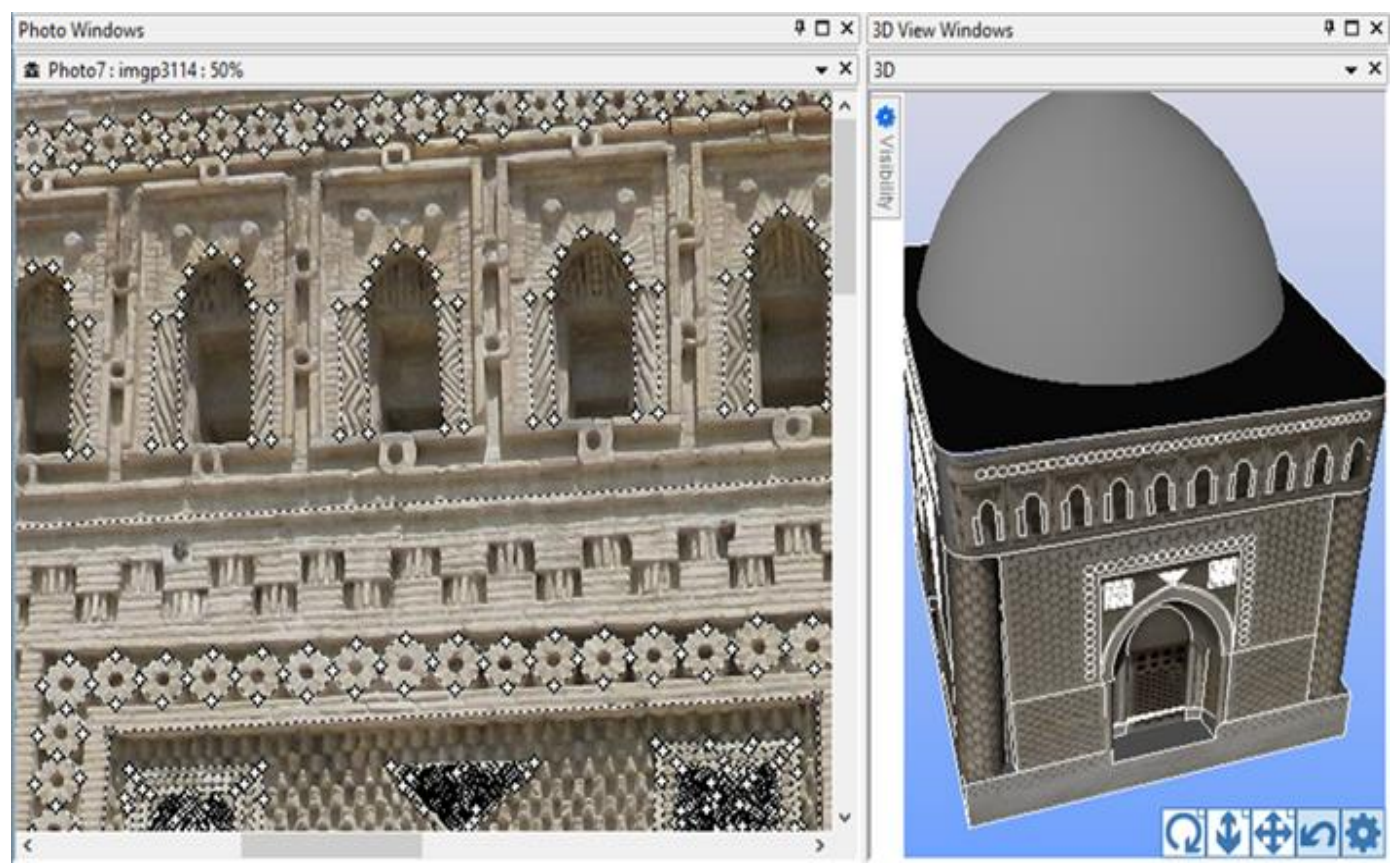

Fig. 10. Drawing Detail 


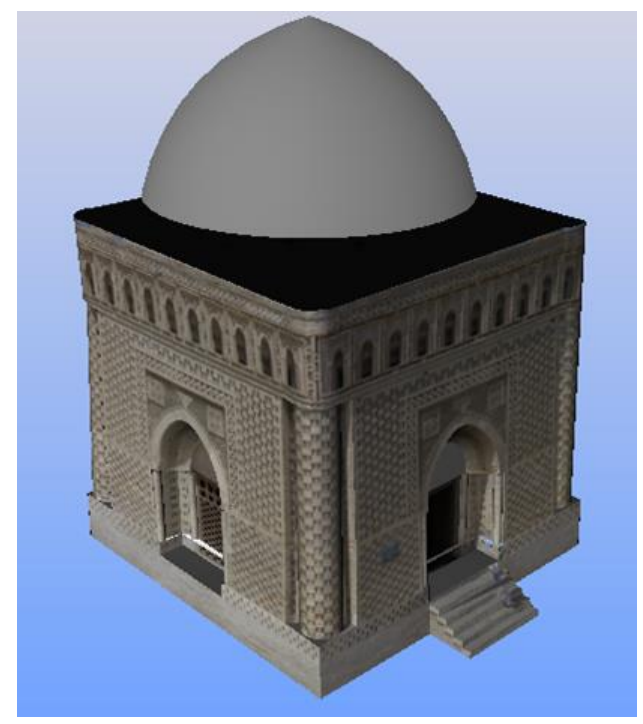

Fig. 11. 3D model

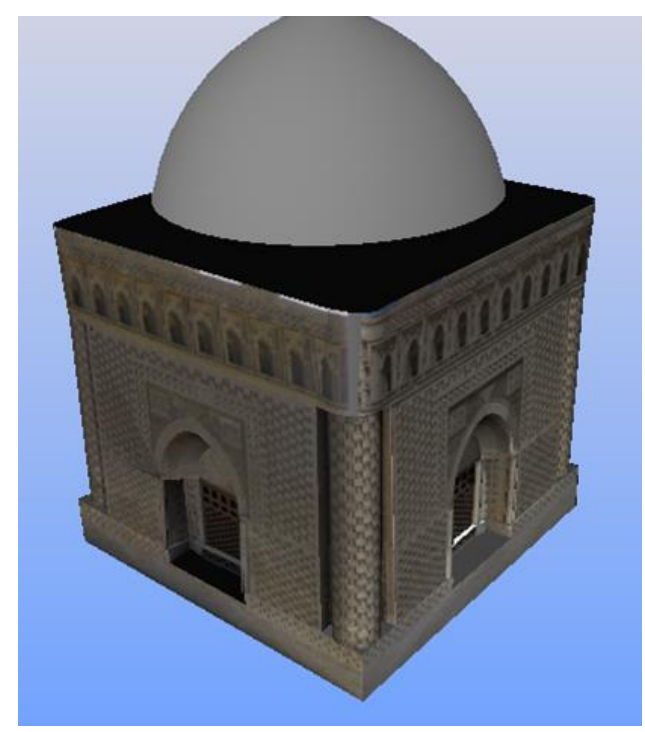

Fig. 12. 3D model

Figures 11 and 12 show a high-quality 3D model of the Ismoil Somoniy Tomb.

\section{CONCLUSIONS}

The use of advanced technologies in the documentation of historical and cultural heritage is necessary to achieve both accurate and rapid and effective results. The development of the methods used in the documentation and monitoring of cultural 
heritage is important in terms of both architectural history and archeology research. Architectural photogrammetry is a documentation method. As an indispensable part of architectural conservation projects, the relieves can be obtained with these methods in a sensitive and short time. Plan, section, facade and detail measurements of the monument can be made with traditional methods. Plan measurements of large volumes are difficult. For large objects with sharp geometric lines and highresolution images, close-range photogrammetry yields higher accuracy results.

\section{REFERENCES}

1. Atkinson, K. B. (1996). Close-range Photogrammetry and Machine Vision, Whittles Publishing, Scotland.

2. Callegari, F. (2003). Sustainable Development Prospects for Italian Coastal Cultural Heritage: A Ligurian Case Study, Journal of Cultural Heritage, 4(1), 49-56.

3. Marangoz, A. (2000). Düşük Çözünürlüklü Sayısal Kameralar Üzerine Bir İnceleme, Yıldız Teknik Üniversitesi Fen Bilimleri Enstitüsü Yüksek Lisans Semineri, İstanbul.

4. Nurminen, K., Karjalainen, M., Yu, X., Hyyppä, J. and Honkavaara, E. (2013). Performance of Dense Digital Surface Models Based on Image Matching in the Estimation of Plot-Level Forest Variables, ISPRS Journal of Photogrammetry \& Remote Sensing, 83, 104-115.

5. Sağıroğlu, Ö. (2004). Yersel Fotogrametrik Rölöve Ölçüm Tekniğinin Ömer Duruk Evi Örneği Üzerinde Uygulanması, Gazi Üniversitesi Fen Bilimleri Enstitüsü, Yüksek Lisans Tezi, Ankara.

6. Suveg, I. and Vosselman, G. (2000). 3D Reconstruction of Building Models Technical University of Delft, The Netherlands Photogrammetry and Remote Sensing, IAPRS, Vol. XXXIII, Amsterdam.

7. Şanoğlu, İ., Zeybek, M. and Karauğuz, G. (2013). Photogrammetric Survey and 3D Modeling of Ivriz Rock Relief in Late Hittite Era, Mediterranean Archaeology and Archaeometry, 13(2), 147-157.

8. Yastıkl1, N. (2009). Ortofoto Ders Notları, Yildiz Technical University, İstanbul, Turkey.

9. Yastıklı, N. (2010). Yersel Fotogrametri Ders Notları, Yildiz Technical University, İstanbul, Turkey.

10. Yakar, M. and Yılmaz, H. M. (2008). Kültürel Miraslardan Tarihi Horozluhan'ın Fotogrametrik Rölöve Çalışması ve 3 Boyutlu Modellenmesi, J. Fac.Eng.Arc. Selcuk Univ., 23(2), 25-33.

11. Yakar, M. and Mohammed, O. (2019). Yersel Fotogrametrik Yöntem İle İbadethanelerin Modellenmesi, Journal of Selcuk-Technic, 15(2), 85-95. 
12. https://www.wikiwand.com/en/Bukhara Region, Date of Access: 12.02 .2019

13. https://wanderingwheatleys.com/bukhara-uzbekistan-things-to-do-see/, Date of Access: 14.02.2019

14. https://www.gpsmycity.com/attractions/samanid-mausoleum-36212.html, Date of Access: 21.02.2019

15.https://vision1cyclings.com/puteshestviya/92574-uzbekistandostoprimechatelnosti-grobnica-samanidov-mavzoley-samanidov-v-buhareopisanie-istoriya.html, Date of Access: 04.03.2019

16. https://www.digicamdb.com/specs/pentax_optio-rz18/, Date of Access: 22.06.2019 